\title{
Dam Location Selection in the Basin of Nestos River Using Multicriteria Analysis
}

\author{
S. Deligiorgis ${ }^{1}$ (D) C. Tzimopoulos ${ }^{1} \cdot$ C. Evangelides $^{1}$
}

Received: 28 January 2015 / Accepted: 1 August 2015 / Published online: 8 September 2015

(C) Springer International Publishing Switzerland 2015

\begin{abstract}
Main goal of the project was the study and management of water resources as well as the application of multicriteria analysis in selecting the best location for the construction of a dam in the basin of Nestos river. Nestos river is considered to be one of the largest rivers in Greece, with significant environmental value. The best position for building a dam was examined by applying the methods of Saaty, Compromise programming and the method of Entropy weights. Although multicriteria decision analysis is not a fully objective process, its importance is undeniable. The analysis in this project is treated as an optimization problem of $f=\left(f_{1}, f_{2}, \ldots f_{m}\right)$, where $f_{i}(i=1,2, \ldots m)$ is the set of possible alternative solutions (in the specific problem the set of possible positions of dams $), x_{j},(j=1,2, \ldots n)$ is the set of the various criteria and $f_{i}\left(x_{j}\right),(i=1,2, \ldots m, j=1,2, \ldots n)$ is a crisp value indicating the performance rating of each alternative $f_{i}$. Criteria importance $w_{j}(j=1,2, \ldots m)$ is a reflection of the Decision Maker's (DM) subjective preference as well as the objective characteristics of the criteria themselves. In the case under study, seven possible locations for dam construction were selected for evaluation. For these positions an analysis was carried out using all methods mentioned before in order to rank each dam. The results of these methods are presented and compared.
\end{abstract}

Keywords Basin of Nestos river - Water resources · Multicriteria analysis · Alternative solutions

\section{Introduction}

Water resources management frequently involves the concepts of multiple users, multiple purposes, and multiple objectives. Water engineers and planners should develop a number of reasonable alternatives for public officials to consider. It is important for them to bring into consideration the impact that each alternative might have to the economic, environmental,

S. Deligiorgis

stefdeligiorgis@gmail.com

1 Department of Rural and Surveying Engineering, Aristotle University of Thessaloniki, Thessaloniki, Greece 


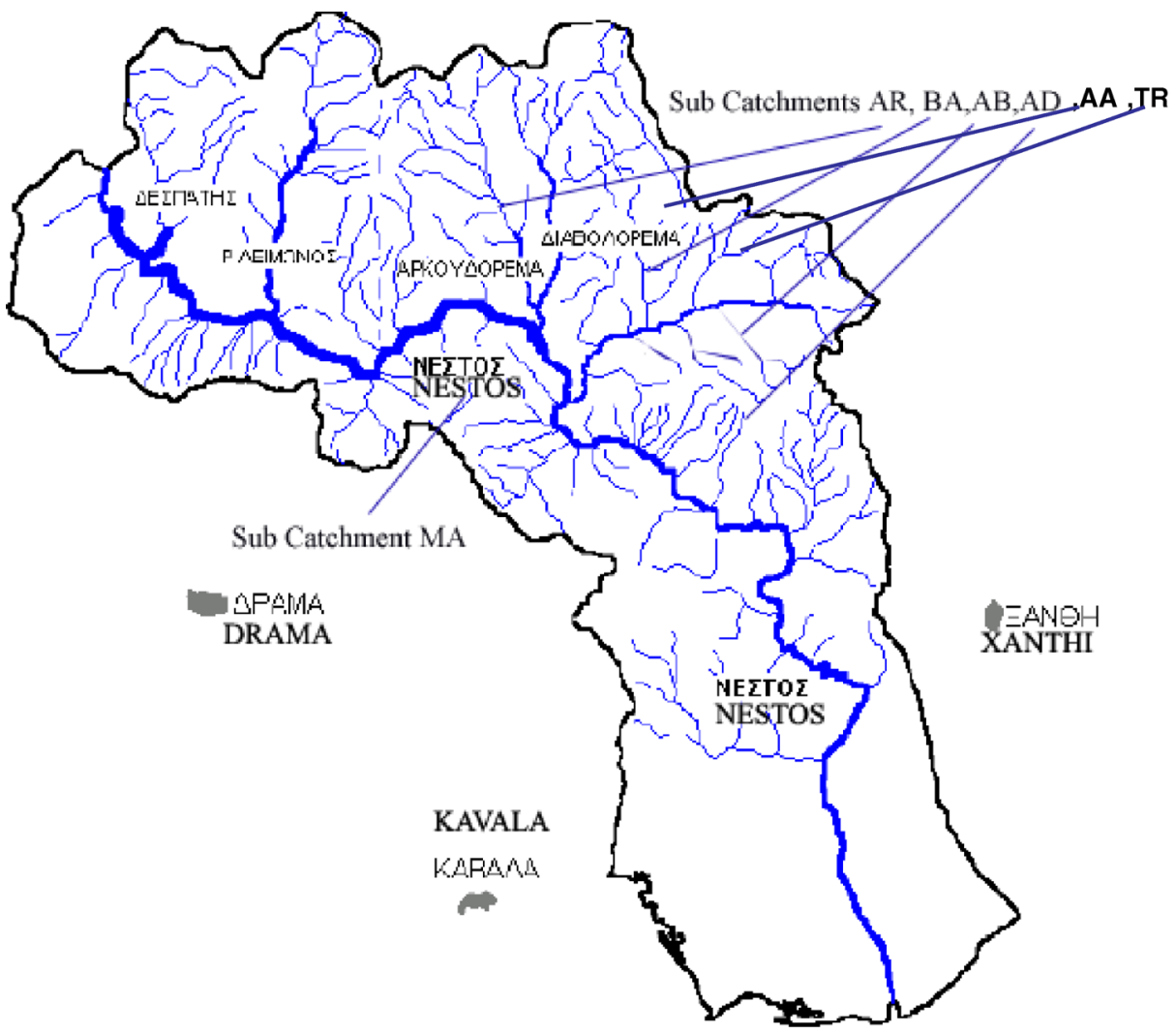

Fig. 1 Catchment of Nestos river

political and social components of the project. A single objective satisfying all aspects of interest is extremely hard to identify (Loucks et al. 1981; Iliadis and Maris 2007).

Multiobjective or multicriterion optimization in water resources planning consists of compromising different conflicting objectives ((Zeleny 1982; Belton and Stewart 2001). A water resources management problem may have various design levels, from a simple structure to a very complex one containing managerial and engineering elements. For the design and evaluation of a

Table 1 Technical data of dams

\begin{tabular}{llllllll}
\hline & Arkoudorema & Agia Barbara & Ano Potamaki & Vathirema & Maurorema & Ano Aetorema & Tsoukali Rema \\
\hline $\begin{array}{c}\text { Stored water } \\
\text { volume }\left(\mathrm{m}^{3}\right)\end{array}$ & 18310127 & 7549478 & 9214425 & 18802784 & 3610918 & 9944026 & 16000801 \\
$\begin{array}{c}\text { Stored water } \\
\text { surface }\left(\mathrm{m}^{2}\right)\end{array}$ & 680197 & 362113 & 379985 & 560769 & 134795 & 490870 & 717622 \\
$\begin{array}{c}\text { Volume }\left(\mathrm{m}^{3}\right) \\
\text { Total cost }(€)\end{array}$ & 3587027 & 2479001 & 4207829 & 5806234 & 3158093 & 3755907 & 5072638 \\
\hline
\end{tabular}

In Table 1, the stored water volume, the surface of the stored water, the volume of the dam, and the cost of each dam is presented. Grading of the dams was carried out according to the criteria, the method and scale of Saaty 
Table 2 Grades of Dams according to Saaty

\begin{tabular}{llllllll}
\hline Annual cost & Arkoudorema & Agias Barbaras & Ano Potamaki & Vathirema & Maurorema & Ano Aetorema & Tsoukali Rema \\
\hline Arkoudorema & 1 & $(1 / 2)$ & 2 & 4 & $(1 / 2)$ & 2 & 2 \\
Agia Barbara & 2 & 1 & 2 & 5 & 2 & 2 & 3 \\
Ano Potamaki & $(1 / 2)$ & $(1 / 2)$ & 1 & 3 & $(1 / 2)$ & $(1 / 2)$ & 2 \\
Vathirema & $(1 / 4)$ & $(1 / 5)$ & $(1 / 3)$ & 1 & $(1 / 4)$ & $(1 / 4)$ & $(1 / 2)$ \\
Maurorema & 2 & $(1 / 2)$ & 2 & 4 & 1 & 2 & 3 \\
Ano Aetorema & $(1 / 2)$ & $(1 / 2)$ & 2 & 4 & $(1 / 2)$ & 1 & 2 \\
Tsoukali Rema & $(1 / 2)$ & $(1 / 3)$ & $(1 / 2)$ & 2 & $(1 / 3)$ & $(1 / 2)$ & 1 \\
\hline
\end{tabular}

complex structure (for example a surface reservoir) a variety of parameters are incorporated in the design and increase the conflicting objectives. Many methods have been evolved for the evaluation of the above problems: ELECTRE I (Roy 1968), AHP (Saaty 1975, 1977, 1980; Kamal et al. 2001; Pantouvakis and Manoliadis 2008), ELECTRE II and ELECTRE III (Belton and Stewart 2001), PROMHTHEE I and II, (Brans and Vincke 1985), Compromise Programming (Zeleny 1974, 1982), MCQA-I and MCQA-II (Duckstein et al. 1991), etc.

\section{Problem Statement}

The area under study is the basin of the river Nestos in Greek territory (Fig. 1). Nestos River originates from mount Rila in Bulgaria and spreads in West Bulgaria and Northern Greece. Nestos river enters Greece from the north west of Drama through mounts Orvilos and Rodopi. In the initial section is divided into two arteries, the White and Black Nestos and then joins other tributaries from which the larger ones are Despatis, Diavolorema and Arkoudorema. The river has a total length of $234 \mathrm{~km}$ of which 130 compose the Greek part. The catchment area is $6.178 \mathrm{~km}^{2}$, of which about $60 \%$ belongs to Bulgaria. The slopes of the river are steep as it is surrounded by bold mountains and peaks with high altitudes.

Nestos basin is highly mountainous with rich aquatic resources. Mountain areas are characterized by a humid continental climate, while the lowlands by a mediterranean climate, with dry months from June to September and the rest of the months mild. In the lowlands, the average monthly air temperature of the warmest months of the year does not exceed $28{ }^{\circ} \mathrm{C}$, while the daily average is often greater than $30{ }^{\circ} \mathrm{C}$, with the extreme values 35 and $40{ }^{\circ} \mathrm{C}$ during the day. The monthly average air temperature for the cold months is above $0{ }^{\circ} \mathrm{C}$, with

Table 3 Annual cost grading

\begin{tabular}{ll}
\hline & Annual cost \\
\hline Arkoudorema & 0.165 \\
Agia Barbara & 0.266 \\
Ano Potamaki & 0.108 \\
Vathirema & 0.041 \\
Maurorema & 0.211 \\
Ano Aetorema & 0.137 \\
Tsoukali Rema & 0.072 \\
\hline
\end{tabular}


Table 4 Final normalized values of the criteria on the Dams

\begin{tabular}{|c|c|c|c|c|c|c|c|c|}
\hline & \multirow{2}{*}{$\begin{array}{l}\mathrm{C}_{1} \\
\text { Annual } \\
\text { cost }\end{array}$} & \multirow{2}{*}{$\begin{array}{l}\mathrm{C}_{2} \\
\text { Flood } \\
\text { protection }\end{array}$} & \multirow{2}{*}{$\begin{array}{l}\mathrm{C}_{3} \\
\text { Environment - } \\
\text { Aesthetic landscape }\end{array}$} & \multirow{2}{*}{$\begin{array}{l}\mathrm{C}_{4} \\
\text { Energy }\end{array}$} & \multirow{2}{*}{$\begin{array}{l}\mathrm{C}_{5} \\
\text { Economic } \\
\text { development }\end{array}$} & \multirow{2}{*}{$\begin{array}{l}\mathrm{C}_{6} \\
\text { Irrigations }\end{array}$} & \multirow{2}{*}{$\begin{array}{l}\mathrm{C}_{7} \\
\text { Accessibility }\end{array}$} \\
\hline & & & & & & & & \\
\hline $\mathrm{F}_{1}$ & Arkoudorema & 0.165 & 0.216 & 0.205 & 0.176 & 0.186 & 0.268 & 0.139 \\
\hline $\mathrm{F}_{2}$ & Agia Barbara & 0.266 & 0.072 & 0.088 & 0.059 & 0.068 & 0.076 & 0.088 \\
\hline $\mathrm{F}_{3}$ & Ano Potamaki & 0.108 & 0.097 & 0.108 & 0.080 & 0.089 & 0.106 & 0.108 \\
\hline $\mathrm{F}_{4}$ & Vathirema & 0.041 & 0.279 & 0.170 & 0.297 & 0.246 & 0.168 & 0.221 \\
\hline $\mathrm{F}_{5}$ & Maurorema & 0.211 & 0.035 & 0.035 & 0.038 & 0.039 & 0.035 & 0.167 \\
\hline $\mathrm{F}_{6}$ & Ano Aetorema & 0.137 & 0.126 & 0.137 & 0.107 & 0.125 & 0.134 & 0.056 \\
\hline $\mathrm{F}_{7}$ & Tsoukali Rema & 0.072 & 0.175 & 0.257 & 0.243 & 0.246 & 0.214 & 0.221 \\
\hline
\end{tabular}

extreme values of up to -14 or up to $-20{ }^{\circ} \mathrm{C}$ at Kato Nevrokopi due to pockets created by cold masses moving through the mountains.

The weather stations of Xanthi, Drama and Chrisoupoli provide rainfall and temperature data for the years 1975-1997. The meteorological station of Thesavros dam provides for the years 1989-2002 only annual rainfall data and finally the meteorological station of Nikiforos provides only monthly rainfall data for the years 1977-2002. According to the study of the Distribution of Rainfall in the Region of Eastern Macedonia and Thrace (Baka 2006) the average annual rainfall is $660 \mathrm{~mm}$ for the period 1964-1998 and the $70.2 \%$ occurs during the semester October - March.

The region is primarily agricultural and two dams exist in the area, Thesavros and Platanovrisi. The area is rich in water resources so the construction of a new dam is considered with storage capacity between 3 and $18 \mathrm{Mm}^{3}$.

\subsection{Study Area}

The analysis in this project is applied in optimizing $\mathrm{f}_{\mathrm{i}}=\left(\mathrm{f}_{1}, \mathrm{f}_{2}, \ldots \mathrm{f}_{\mathrm{m}}\right)$, possible alternative solutions (in this case the set of possible positions of dams), $\mathrm{x}_{\mathrm{j}},(\mathrm{j}=1,2, \ldots \mathrm{n})$ is the set of the various criteria, and $f_{i}\left(x_{j}\right),(i=1,2, \ldots m, j=1,2, \ldots n)$ is a crisp value indicating the performance rating of each alternative $f_{i}$. The matrix $f_{i}\left(x_{j}\right)$ is called decision matrix of the data. Criteria importance $w_{j}(j=$ $1,2, \ldots \mathrm{m})$ is a reflection of the Decision Maker's subjective preference as well as the objective characteristics of the criteria themselves. Seven possible locations for dam construction in Nestos river basin (Deligiorgis et al. 2014), were selected (Fig. 1): $F_{1}=$ Arkoudorema-AR, $F_{2}=$ Saint

Table 5 Weights of criteria

\begin{tabular}{llllllll}
\hline & $\mathrm{C} 1$ & $\mathrm{C} 2$ & $\mathrm{C} 3$ & $\mathrm{C} 4$ & $\mathrm{C} 5$ & $\mathrm{C} 6$ & $\mathrm{C}$ \\
$\mathrm{C} 1$ & 1 & 2 & 2 & 3 & 2 & 3 & 7 \\
$\mathrm{C} 2$ & 0.5 & 1 & 2 & 3 & 2 & 3 & 6 \\
$\mathrm{C} 3$ & 0.5 & 0.5 & 1 & 2 & 2 & 2 & 5 \\
$\mathrm{C} 4$ & 0.333 & 0.333 & 0.5 & 1 & 0.5 & 1 & 3 \\
$\mathrm{C} 5$ & 0.5 & 0.5 & 0.5 & 2 & 1 & 2 & 4 \\
$\mathrm{C} 6$ & 0.333 & 0.333 & 0.5 & 1 & 0.5 & 1 & 3 \\
$\mathrm{C} 7$ & 0.143 & 0.167 & 0.2 & 0.333 & 0.25 & 0.333 & 1 \\
\hline
\end{tabular}


Table 6 Weights of Criteria according to Saaty

\begin{tabular}{lllllll}
\hline W1 & W2 & W3 & W4 & W5 & W6 & W7 \\
\hline 0.284 & 0.227 & 0.163 & 0.081 & 0.13 & 0.081 & 0.032 \\
\hline
\end{tabular}

Barbara- $\mathrm{AB}, \mathrm{F}_{3}=$ Ano Potamaki-AD, $\mathrm{F}_{4}=$ Vathirema-BA, $\mathrm{F}_{5}=$ Maurorema-MA, $\mathrm{F}_{6}=$ Ano Aetorama-AA, $\mathrm{F}_{7}=$ Tsoukali Rema-TR. For these positions a study was made for finding quantities to evaluate each dam on seven criteria $\left(C_{1}=\right.$ cost, $C_{2}=$ protection from floods, $C_{3}=$ environment, $\mathrm{C}_{4}=$ energy, $\mathrm{C}_{5}=$ economical development, $\mathrm{C}_{6}=$ irrigation and $\mathrm{C}_{7}=$ accessibility).

The geometric characteristics of the dams (height, cross section, volume), in each location were calculated. The run-off was estimated from the rainfall data and calculations were carried out for the surface and the storage capacity of the reservoirs. The construction cost was estimated as $22.227 € / \mathrm{m}^{3}$.

\subsubsection{Criteria}

Criterion $\mathbf{C}_{\mathbf{1}}$ (cost).

Based on Table 1 and the scale of Saaty, Table 2 was formed which is a reciprocal matrix.

Criterion $\mathbf{C}_{2}$ (protection from floods).

Following Saaty's method Table 2 was normalized and Table 3 shows the final grading of the Dams.

Flood protection is proportional to the volume of water stored in the dam. In this case, the dam with the largest stored volume is considered as optimum.

Criterion $\mathbf{C}_{\mathbf{3}}$ (environment).

In this criterion, the water surface created by the reservoir is considered. This is reflected in the range of Saaty, by assigning to the larger area the higher value.

\section{Criterion $\mathbf{C}_{4}$ (energy).}

This criterion is linked to the height of the dam and the volume of the reservoir created for the seven scenarios that are considered in the paper. Therefore, one way to assess each dam relative to the energy that can provide a future hydroelectric plant is the comparison of the product of the water level height in the reservoir and the volume. The largest of these is considered as excellent in the scale of Saaty and accordingly the rest are graded.

Table 7 Weights of Criteria using entropy

\begin{tabular}{lllllll}
\hline W1 & W2 & W3 & W4 & W5 & W6 & W7 \\
\hline 0.132 & 0.157 & 0.125 & 0.201 & 0.155 & 0.142 & 0.088 \\
\hline
\end{tabular}


Table 8 The rating order of the alternatives (Compromise programming)

\begin{tabular}{llllllll}
\hline $\mathrm{L}_{1}$ & $\mathrm{~F}_{1}(0.316)>$ & $\mathrm{F}_{7}(0.377)>$ & $\mathrm{F}_{4}(0.383)>$ & $\mathrm{F}_{2}(0.595)>$ & $\mathrm{F}_{6}(0.607)>$ & $\mathrm{F}_{3}(0.723)>$ & $\mathrm{F}_{5}(0.762)$ \\
$\mathrm{L}_{2}$ & $\mathrm{~F}_{1}(0.156)>$ & $\mathrm{F}_{6}(0.259)>$ & $\mathrm{F}_{7}(0.265)>$ & $\mathrm{F}_{2}(0.275)>$ & $\mathrm{F}_{4}(0.293)>$ & $\mathrm{F}_{3}(0.314)>$ & $\mathrm{F}_{5}(0.336)$ \\
$\mathrm{L}_{\infty}$ & $\mathrm{F}_{1}(0.127)>$ & $\mathrm{F}_{6}(0.163)>$ & $\mathrm{F}_{2}(0.193)>$ & $\mathrm{F}_{3}(0.2)>$ & $\mathrm{F}_{5}(0.227)>$ & $\mathrm{F}_{7}(0.245)>$ & $\mathrm{F}_{4}(0.284)$ \\
\hline
\end{tabular}

Table 9 The rating order of the alternatives (Saaty)

\begin{tabular}{llllllll}
\hline Saaty & $F_{1}(0.194)>$ & $F_{4}(0.179)>$ & $F_{7}(0.178)>$ & $F_{2}(0.129)>$ & $F_{6}(0.127)>$ & $F_{3}(0.1)>$ & $F_{5}(0.09)$ \\
\hline
\end{tabular}

Criterion $\mathbf{C}_{5}$ (economical development).

This criterion relates to the potential economic growth of the region. Construction of hydroelectric power station and at the same time irrigation of agricultural land is considered. So, the criterion of economic growth is calculated as the average of the energy and irrigation criteria.

\section{Criterion $\mathbf{C}_{6}$ (irrigation).}

This criterion relates to the volume occupied by the stored water and the size of irrigated land.

Criterion $\mathbf{C}_{7}$ (accessibility).

For this criterion the distance of each dam from the nearest roadway is considered. Zero distance is considered as optimal (dams very close to road) and as the worst $5 \mathrm{~km}$. This assessment is reflected on a scale of Saaty.

The above considerations and Table 1 allowed the grading of criteria $\mathrm{C}_{2} \sim \mathrm{C}_{7}$, in the same way that the dams were graded according to criterion $C_{1}$. Thus, Table 4 gives the overall rating of all dams for all criteria in dimensionless scale:

Weights Evaluation of the criteria weights of the problem:

During this step, the comparison scale of Saaty is utilized and the following pairwise Table 5 is formed.

Finally, after finding and normalizing the eigenvector of Table 5, the resulting Table 6 shows the weights of each criterion according to Saaty.

Table 10 The rating order of the alternatives using weighs of entropy method (Compromise programming)

\begin{tabular}{llllllll}
\hline $\mathrm{L}_{1}$ & $\mathrm{~F}_{4}(0.242)>$ & $\mathrm{F}_{7}(0.256)>$ & $\mathrm{F}_{1}(0.312)>$ & $\mathrm{F}_{6}(0.649)>$ & $\mathrm{F}_{2}(0.734)>$ & $\mathrm{F}_{3}(0.739)>$ & $\mathrm{F}_{5}(0.841)$ \\
$\mathrm{L}_{2}$ & $\mathrm{~F}_{1}(0.137)>$ & $\mathrm{F}_{7}(0.142)>$ & $\mathrm{F}_{4}(0.153)>$ & $\mathrm{F}_{2}(0.312)>$ & $\mathrm{F}_{6}(0.254)>$ & $\mathrm{F}_{3}(0.291)>$ & $\mathrm{F}_{5}(0.356)$ \\
$\mathrm{L}_{\infty}$ & $\mathrm{F}_{1}(0.094)>$ & $\mathrm{F}_{7}(0.114)>$ & $\mathrm{F}_{4}(0.132)>$ & $\mathrm{F}_{6}(0.147)>$ & $\mathrm{F}_{3}(0.168)>$ & $\mathrm{F}_{2}(0.185)>$ & $\mathrm{F}_{5}(0.201)$ \\
\hline
\end{tabular}


Table 11 The rating order of the alternatives using weights of entropy method.(Saaty)

$\begin{array}{llllllll}\text { Saaty } & F_{4}(0.212)> & F_{7}(0.206)> & F_{1}(0.196)> & F_{6}(0.12)> & F_{2}(0.098)> & F_{3}(0.097)> & F_{5}(0.071)\end{array}$

\subsubsection{Criteria Weights According to the Entropy Method}

The weights of the criteria according to the entropy method are presented in Table 7 and further explained in the appendix.

\section{Results and Discussion}

The previous methods are used in the case of finding the best possible solution between the 7 dam positions which have been examined. The decision matrix and the weights vector matrix of seven alternatives $\left(\mathrm{F}_{1}, \mathrm{~F}_{2}, \mathrm{~F}_{3}, \mathrm{~F}_{4}, \mathrm{~F}_{5}, \mathrm{~F}_{6}, \mathrm{~F}_{7}\right)$ are presented in Tables 5 and 6.

1. Applying the Compromise Programming (see Appendix), and according to the closeness measure, the rating order of the seven alternatives is presented below in Table 8. In this table, the symbol $>$ signifies better than.

2. Table 9 shows the rating order of the seven alternatives, applying the Saaty method.

3. The same procedure is applied using as weights those obtained by the entropy method (Table 7), and the initial Decision matrix (Table 5).

3.1 Table 10 presents the rating order of the seven alternatives, applying the Compromise Programming.

3.2 Table 11 presents the rating order of the seven alternatives applying the Saaty method.

\section{Conclusions}

The $\mathrm{L}_{1}$ norm of Compromise Programming and the Saaty method arrive at the same results, having a difference to the second and third order. The $\mathrm{L}_{2}$ and $\mathrm{L}_{\infty}$ norms agree with $\mathrm{L}_{1}$ norm and with Saaty method as far as the best solution $\left(\mathrm{F}_{1}=\right.$ Arkoudorema), but have different hierarchical order of the other alternatives.

Again the $\mathrm{L}_{1}$ norm of Compromise Programming and the Saaty method agree absolutely having the same qualitative results in the hierarchical order. The $\mathrm{L}_{2}$ and $\mathrm{L}_{\infty}$ norms disagree completely with $\mathrm{L}_{1}$ norm and with Saaty method in the hierarchical order of the alternatives.

Saaty method shows important differences using Entropy weights, because of the different philosophy in the way of calculating the criteria weights.

Saaty method and method of Compromise Programming $\left(\mathrm{L}_{1}\right.$ norm) give the same results in terms of the most ideal dam position and the same ranking of the dam selection, providing that the same method (as far as the weights) is used.

For Compromise Programming according to Yu (1973) it appears that the group utility sum ( $\mathrm{L}_{1}$ norm) of the compromise solution is maximized, and as $\mathrm{p}$ becomes higher, the sum of utilities becomes smaller. $\left(\mathrm{L}_{\infty}<\mathrm{L}_{2}<\mathrm{L}_{1}\right)$

Regarding the weights of the criteria, many other methods have been proposed and for each one the inventor claims that is the best. 


\section{Appendix}

\section{Compromise Programming}

Compromise solutions are those which are the closest, by some distance measure, to the ideal one (Yu 1973; Zeleny 1974; Baka 2006; Tzimopoulos et al. 2009; Tzimopoulos and Evangelides 2009). Among all achievable scores for the $\mathrm{i}^{\text {th }}$ criterion there is at least one value that is preferred to all remaining ones. For example $f^{*}=\operatorname{Max}_{x} f_{i}(x), i=1,2, \ldots, n$. The vector $f^{*}$ whose elements are such maxima is called ideal vector: $f^{*}=\left(f_{1}^{*}, \ldots ., f_{n}^{*}\right)$. One of the most frequently used measures of closeness is a family of $\mathrm{L}_{\mathrm{p}}$ metrics, defined as follows:

$$
L_{p}=\left[\sum_{i=1}^{n} w_{i}^{p}\left(f_{i}^{*}-f_{i}(x)\right)^{p}\right]^{1 / p}, \quad 1 \leq p \leq \infty
$$

where weights $\mathrm{w}_{\mathrm{i}}$ are either assessed subjectively by the DM or derived from the preference structure.Because the units and the achievement levels of the objectives may be different, the degree of closeness must be normalized by using relative deviations rather than absolute ones (Zeleny 1982). The normalized degree of closeness $d_{i}(x)$ is expressed by:

$$
d_{i}^{*}=\frac{f_{i}^{*}-f_{i}^{\text {Min }}}{f_{i}^{\text {Max }}-f_{i}^{\text {Min }}},
$$

where $f_{i}^{M a x}, f_{i}^{M i n}$ are the Maximum and Minimum value of $\mathrm{f}_{\mathrm{i}}(\mathrm{x})$, respectively. For each criterion $f_{i}^{M a x}=f_{i}^{*}$ is determined and the above function (1) becomes in normalized form:

$$
\begin{gathered}
L_{p}=\left[\sum_{i=1}^{n} w_{i}^{p}\left\{\frac{\left(f_{i}^{\text {Max }}-f_{i}(x)\right)}{\left(f_{i}^{\text {Max }}-f_{i}^{\min }\right.}\right\}^{p}\right]^{1 / p}=\left[\sum_{i=1}^{n} w_{i}^{p}\left\{1-\frac{f_{i}(x)-f_{i}^{\text {Min }}}{f_{i}^{\text {Max }}-f_{i}^{\text {Min }}}\right\}^{p}\right]^{1 / p} \\
=\left[\sum_{i=1}^{n} w_{i}^{p}\left(1-d_{i}(x)\right)^{p}\right]^{1 / p}, \quad 1 \leq p \leq \infty
\end{gathered}
$$

where the ideal relative distance is $d_{i}^{*}=(1,1, \ldots . .1)$. The element $\mathrm{p}$ is a parameter called «factor of compensation». The previous norm for $\mathrm{p}=1,2, \infty$ takes the following forms:

$$
\begin{gathered}
\mathrm{p}=1 \quad \mathrm{~L}_{1}(w, \mathrm{k})=\left\{\sum_{\mathrm{j}=1}^{\mathrm{n}} \mathrm{w}_{\mathrm{j}}\left(1-\mathrm{d}_{\mathrm{ij}}\right)\right\} \quad \text { (Manhattan metric) } \\
\mathrm{p}=2 \quad \mathrm{~L}_{2}(w, \mathrm{k})=\left\{\sum_{\mathrm{j}=1}^{\mathrm{n}} \mathrm{w}_{\mathrm{j}}^{2}\left(1-\mathrm{d}_{\mathrm{ij}}\right)^{2}\right\}^{1 / 2} \quad(\text { Euclidean metric) } \\
\mathrm{p}=\infty \quad \mathrm{L}_{\infty}(w, \mathrm{k})=\operatorname{Max}_{j}\left\{\mathrm{w}_{\mathrm{j}}\left(1-\mathrm{d}_{\mathrm{ij}}\right)\right\}, \mathrm{j}=1,2, \ldots, \mathrm{n} \quad \text { (Chebychevmetric) }
\end{gathered}
$$

Two parameters appear in Compromise Programming:

1) Parameter $\mathrm{p}$, which reflects the importance of maximum deviation from the ideal solution and the connection between the criteria. As Yu (1973) reports, the sum of individual utility 
$(p=1)$ may be interpreted as the group utility and for $p \rightarrow \infty$ the maximum individual regret appears, that is the lowest sum of individual utility. Finally $\mathrm{L}_{\infty}<\mathrm{L}_{2}<\mathrm{L}_{1}$.

2) The weight $w_{i}$ of every criterion $i$ which declares its importance in this project.

Saaty method

Saaty's method is simple and is described in the next steps:

1) Selection of criteria and alternative solutions. In this first step alternatives solutions are selected $F_{j},(j=1, \ldots, m)$ and criteria $C_{i},(i=1, \ldots, n)$. These criteria will be evaluated for every solution.

2) Evaluation of criteria for every solution. A matrix $A=n \times m$ is created, where in every element $a_{i j}$ alternative solution $i$ is evaluated relatively to the criterion $j$ in a scale of evaluation from 1 to 9, depending on how better or worse this solution is, compared to others after the results of a survey that has been carried out.

3) Pairwise comparison of the alternative solutions for each criterion creating as many matrices as the criteria and evaluating the solutions weights for every criterion.

4) Evaluation of the weights for the criteria of the project with the method of pairwise comparison.

5) Finally, evaluation and selection of the best solution after the use of the equation (7) for the Analytical Hierarchy Process:

$$
A_{A H P}=\max _{j} \sum_{i=1}^{N} w_{i} a_{j i}, j=1,2, \ldots M
$$

\section{Method of Entropy weights}

Shannon's method of Entropy (Shannon 1948a, b) is completely appropriate for calculating relative intensities of contrasts for economic problems and shows the average internal information transmitted to the decision maker. According to Zeleny (1974), the measure of Entropy shows clearly the quantity of the decision's information in every element of the decision matrix. Entropy constitutes a measure of uncertainty formed by the use of probability theory. This shows that a depressed distribution represents more uncertainty than a rough distribution. For the assessment of objective weighs by the measure of entropy, decision matrix $x_{j}^{i}$ is normalized for every criterion $\mathrm{C}_{\mathrm{j}}\left(\mathrm{C}_{\mathrm{j}}=1,2, \ldots \mathrm{m}\right)$ according to the equation:

$$
r_{j}^{i}=\frac{x_{j}^{i}}{\sum_{i=1}^{n}\left(x_{j}^{i}\right)} .
$$

Consequently, a normalized matrix which represents the related performance of every alternative activity $x^{i}$ is created:

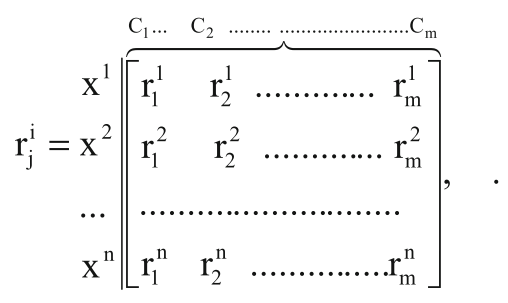


The raw data is normalized to eliminate anomalies with different measurement units and scales. This process transforms different scales and units among various criteria into common measurable units to allow the comparison of different criteria. The quantity of information that is included in the previous matrix and arise from every criterion $\mathrm{C}_{\mathrm{j}}\left(\mathrm{C}_{\mathrm{j}}=1,2, \ldots, \mathrm{m}\right)$ can be calculated by the value of entropy $\mathrm{e}_{\mathrm{j}}$ :

$$
e_{j}=-k \sum_{i=1}^{n} r_{j}^{i} \ln r_{j}^{i}
$$

where $\mathrm{k}=1 / \ln (\mathrm{n})$ is a proof which ensures the operator $0 \leq \mathrm{e}_{\mathrm{j}} \leq 1$. The rate of deviation $\left(\mathrm{d}_{\mathrm{j}}\right)$ of the average internal information that is included in every criterion $\mathrm{C}_{\mathrm{j}},(\mathrm{j}=1,2, \ldots, \mathrm{m})$ is calculated by the equation :

$$
d_{j}=1-e_{j}
$$

The deviation $\left(d_{j}\right)$ represents the inherent contradictions' intensity of the criterion $C_{j}$. The objective weight for every criterion is given by the next expression:

$$
w_{j}=\frac{d_{j}}{\sum_{k=1}^{m} d_{k}}
$$

\section{References}

Baka M (2006) Water resources management by methods of multicriteria analysis (compromise programming) and application in the area of Nestos River. MSc thesis. Aristotle University of Thessaloniki. Thessaloniki. Greece

Belton V, Stewart T (2001) Multiple criteria decision analysis. Springer US, pp. 372

Brans JP, Vincke P (1985) A preference ranking organisation method,-(The PROMETHEE method for multiple criteria decision-making). Manag Sci 31(6):647-656

Deligiorgis S, Tzimopoulos C, Evangelides C (2014) Multicriteria decision analysis in the Basin of Nestos River. 12th International Conference on Protection and Restoration of the Environment. June 29 to July 3. Skiathos island. Greece, $37-42$

Duckstein L, Bobée B, Ashkar F (1991) A multiple criteria decision modelling approach to selection of estimation techniques for fitting extreme floods. Stochastic Hydrol Hydraul 5:227-238

Kamal M, Al S, Al H (2001) Application of the AHP in project management. Int J Proj Manag 19:19-27

Iliadis L, Maris F (2007) An artificial neural network model for mountainous water-resources management: the case of Cyprus mountainous watersheds. Env Modelling Software 22(7):1066-1072

Loucks D, Stedinger J, Haith D (1981) Water resources systems planning and analysis. Prentice Hall, Inc, New Jerrsey

Pantouvakis JP, Manoliadis OG (2008) A compromise programming model for site selection of borrow pits. Construc Manage Econ 26:433-446

Roy B (1968) Classement et choix en présence de points de vue multiples (la méthode ELECTRE). La Revue d' Informatique et de Recherche Opérationelle (RIRO) 8:57-75

Saaty TL (1975) Hierarchies and priorities-eigenvalue analysis. University of Pennsylvania

Saaty TL (1977) A scaling method for priorities in hierarchical structures. J Math Psychol 15:234-281

Saaty TL (1980) The analytic hierarchy process. McGraw-Hill Book Co., New York

Shannon CE (1948a) A Mathematical Theory of Communication. The Bell System Technical Journal 27(3):279_ 423

Shannon Ce (1948b) A Mathematical Journal of Communication. The Bell System Technical Journal 27(4):623656

Tzimopoulos C, Evangelides C (2009) Decision making in water resources with fuzzy information. GNEST 13: 317-324 
Tzimopoulos C, Giannopoulos S, and Evangelides C (2009) Multicriteria analysis for the management of water places with the introduction of fuzzy logic. Application in the hydrologic basin of Nestos river. 6th EGME Conference 2009, Thessaloniki, Greece

Yu PL (1973) A class of solutions for group decision problem. Manag Sci 19(8):936-946

Zeleny M (1974) A concept of compromise solutions and the method of the displaced ideal. Comput Ops Res 1: 439-996, Pergamon Press. Printed in Great Britain

Zeleny M (1982) Multiple criteria decision making. McGraw-Hill Book Co, New York 